\title{
Efeito de Dois Indutores de Resistência sobre a Severidade do Mal-do-Panamá*
}

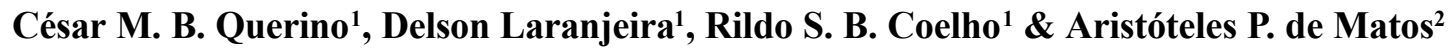 \\ ${ }^{1}$ Universidade Federal Rural de Pernambuco, Departamento de Agronomia / Fitossanidade, R. Dom Manuel de \\ Medeiros, S/N - Dois Irmãos, Recife, PE, CEP 52171-900, Fax (081) 3302-1205, e-mail: rejadel@ yahoo.com.br; \\ ${ }^{2}$ Embrapa Mandioca e Fruticultura, Rua Embrapa s/n, Cx. Postal 007, Cruz das Almas, BA, CEP 44380-000
}

(Aceito para publicação em 24/01/2005)

Autor para correspondência: Delson Laranjeira

QUERINO, C.M.B., LARANJEIRA, D., COELHO, R.S.B. \& MATOS, A.P. Efeito de dois indutores de resistência sobre a severidade do mal-do-Panamá. Fitopatologia Brasileira 30:239-243. 2005.

\section{RESUMO}

O mal-do-Panamá, causado por Fusarium oxysporum f. sp. cubense, é um fator limitante à cultura da bananeira (Musa spp.). A medida de controle mais eficiente para essa doença é o cultivo de variedades resistentes. A resistência induzida constitui alternativa a ser avaliada nesse patossistema. Avaliou-se o efeito indutor de resistência de acibenzolar-Smetil (ASM) e ácido DL-b-amino-n-butírico (BABA) sobre germinação e crescimento micelial de F. oxysporum f. sp. cubense in vitro nas dosagens $0 ; 0,050 ; 0,100 ; 0,150 ; 0,200 ; 0,250$ e $0,500 \mathrm{mg}^{-1} \mathrm{ml}^{-1}$ e $0 ; 0,525 ; 1,050 ; 1,575 ; 2,100 ; 2,625$ e 3,150 mg.ml ${ }^{-1}$, respectivamente, utilizando-se $F$. oxysporum f. sp. cubense na concentração 1 x $10^{3}$ conídios.ml ${ }^{-1}$. Os ASM e BABA foram pulverizados nas dosagens $0 ; 0,050 ; 0,100 ; 0,150 ; 0,200 ; 0,250 \mathrm{mg}^{\mathrm{ml}} \mathrm{I}^{-1}$ e $0 ; 0,525 ; 1,050 ; 1,575 ; 2,100 ; 2,625$ mg.ml 1, respectivamente, sobre bananeiras 'Maçã' e 'Grande Naine' micropropagadas, mantidas em casa de vegetação. As raízes foram inoculadas por imersão em suspensão de $F$. oxysporum f. sp. cubense 1 x $10^{3}$ conídios.ml ${ }^{-1}$, quatro, seis e oito semanas após indução. Avaliou-se a severidade da doença 20 dias após inoculação através de escala de notas. O BABA, 2,100 mg.ml ', propiciou 35,29\% de redução na severidade de doença em banana 'Maçã', aplicado quatro semanas antes da inoculação com F. oxysporum f. sp. cubense. O ASM, 0,500 mg. $\mathrm{ml}^{-1}$, inibiu a germinação de conídios in vitro. O BABA, nas dosagens testadas, não interferiu no crescimento micelial. Em 'Grande Naine', BABA, 0,525 mg.ml' ${ }^{-1}$, reduziu a severidade da doença em 21,55\% independente da época de inoculação. Não se constatou efeito do ASM sobre a severidade do mal-do-Panamá.

Palavras-chave adicionais: mal-do-Panamá, resistência sistêmica adquirida, Musa spp.

\section{ABSTRACT \\ Effect of two resistance inducers on Panama disease severity}

Panama disease, caused by Fusarium oxysporum f. sp. cubense, is a limiting factor for banana (Musa spp.) production. The most efficient control measure consists of the use of resistant cultivars. Inducing resistance in the host is an alternative to be evaluated. The present investigation studied the effect of acibenzolar-S-methyl (ASM) and DL-b-amino-n-butyric acid (BABA) resistance inducers on the germination and mycelial growth of $F$. oxysporum $\mathrm{f}$. sp. cubense in vitro at the following rates of: $0 ; 0.050 ; 0.100 ; 0.150 ; 0.200 ; 0.250$ and $0.500 \mathrm{mg}^{-\mathrm{ml}^{-1}}$ and $0 ; 0.525 ; 1.050 ; 1.575 ; 2.100 ; 2.625$ and $3.150 \mathrm{mg}^{\mathrm{ml}} \mathrm{m}^{-1}$, respectively, using $F$. oxysporum f. sp. cubense at $1 \times 10^{3}$ conidia. $\mathrm{ml}^{-1}$ as inoculum. The ASM and BABA were sprayed at the

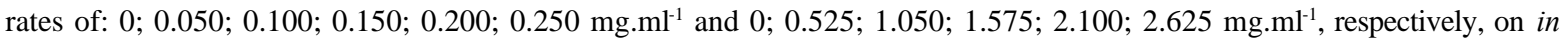
vitro produced banana plants varieties 'Maçã' and 'Grande Naine' under greenhouse conditions. Roots were inoculated by immersion in a conidial suspension of $F$. oxysporum f. sp. cubense at $1 \times 10^{3}$ units. $\mathrm{ml}^{-1}$ four, six and eight weeks after induction. Disease severity was measured 20 days after inoculation using a disease index. The results pointed out that BABA at $2.100 \mathrm{mg} \cdot \mathrm{ml}^{-1}$, decreased disease severity in the var. 'Maçã' by $35.0 \%$ when applied four weeks before inoculation. The ASM at $0.500 \mathrm{mg} \cdot \mathrm{ml}^{-1}$, inhibited in vitro germination of conidia. BA BA at the rates used, did not affect the mycelial growth of the fungus. In 'Grande Naine', BABA at $0.525 \mathrm{mg} \cdot \mathrm{ml}^{-1}$, reduced disease severity by $21.55 \%$ for the inoculation times. No ASM effect was observed for the severity of Panama disease.

Additional keywords: mal-do-Panamá, aquired systemic resistance, Musa spp.

\section{INTRODUÇÃO}

Segunda fruta mais consumida no Brasil, a banana (Musa spp.), além de contribuir para a dieta alimentar de grande parte da população, desempenha importante papel socioeconômico tanto como geradora de renda quanto na

*Parte da Dissertação de Mestrado do primeiro autor. Universidade Federal Rural de Pernambuco (2004) fixação do homem no campo (Anuário Brasileiro da Fruticultura, 2003).

A bananeira pode ser afetada por diversos patógenos, com reflexos negativos na produção. Nesse contexto, o maldo-Panamá, causado pelo fungo Fusarium oxysporum Schlecht.: Fr f. sp. cubense (E. F. Smith) Snyd. \& Hans, constitui doença de fundamental importância para a bananicultura mundial, sendo responsável por elevadas perdas na 
produção (Matos et al., 2001). Na primeira metade do século 20 o mal-do-Panamá dizimou os plantios de 'Gros Michel' (AAA) na América Central, até então a principal variedade de banana para exportação, motivando sua substituição por aquelas do subgrupo Cavendish (AAA) (Cordeiro \& Matos, 2003). A medida de controle mais eficiente para essa doença é o cultivo de variedades resistentes (Moreira, 1987; Matos et al., 2001; Querino et al., 2003; Rosales et al., 2003) As dificuldades existentes na transferência da resistência ao maldo-Panamá para variedades suscetíveis (Figueira, 2003), fazem da resistência induzida uma alternativa a ser avaliada nesse patossistema.

$\mathrm{O}$ estudo dos diversos mecanismos de defesa local e sistêmico, constitutivos e induzíveis, desenvolvidos ao longo do processo de co-evolução entre patógeno e hospedeiro revelou a possibilidade de ativação de respostas de defesa sistêmica preventiva em plantas contra patógenos. Essas respostas de defesa, que incluem formação de papila, lignificação de parede celular, produção de espécies reativas de oxigênio (ROS), reação hipersensitiva (HR), expressão de proteínas relacionadas com a patogênese (PRPs), tais como quitinases e glucanases, e acúmulo de metabólitos antimicrobianos, tais como fitoalexinas, são conhecidas como resistência sistêmica adquirida ou SAR (Kessmann et al., 1994; Siegrist et al., 2000). Alguns compostos, a exemplo do acibenzolar-S-metil (ASM) e do ácido DL- $\beta$-amino-n-butírico (BABA) têm se comportado como ativadores de SAR em diversos fitopatossistemas (Görlach et al., 1996; Cohen, 2002).

O presente trabalho teve como objetivo avaliar o efeito in vitro de diferentes dosagens de ASM e BABA sobre germinação de conídios e crescimento micelial de $F$. oxysporum f. sp. cubense, assim como o efeito de diferentes dosagens e épocas de aplicação desses indutores na redução da severidade do mal-do-Panamá em plantas micropropagadas de banana 'Maçã' (AAB) e 'Grande Naine' (AAA) inoculadas com o patógeno, em condições de casa de vegetação.

\section{MATERIAL E MÉTODOS}

\section{Determinação da atividade in vitro do ASM e do BABA sobre a germinação de conídios de $F$. oxysporum f. sp. cubense}

Adicionou-se a placas de Petri contendo $12,5 \mathrm{ml}$ de meio de cultura BDA (Batata-Dextrose-Ágar), 0,1 ml de uma suspensão de inóculo de $F$. oxysporum f. sp. cubense, 1 x $10^{3}$ conídios. $\mathrm{ml}^{-1}$, previamente determinada em hemacitômetro tipo Neubaeur, acrescido de ASM nas dosagens 0; 0,050; 0,$100 ; 0,150 ; 0,200 ; 0,250$ e $0,500 \mathrm{mg} \cdot \mathrm{ml}^{-1}$ e BABA nas dosagens $0 ; 0,525 ; 1,050 ; 1,575 ; 2,100 ; 2,625$ e $3,150{\text { mg. } \mathrm{ml}^{-}}^{-}$ ${ }^{1}$ na relação 1:1. A suspensão foi espalhada sobre o meio de cultura com auxílio de alça de Drigalsk. As placas foram divididas em quatro quadrantes por riscas em sua parte inferior externa, sendo realizadas três leituras ao microscópio ótico por quadrante, após $10 \mathrm{~h}$ de incubação, de forma aleatória. $\mathrm{O}$ mesmo procedimento foi adotado para a testemunha apenas com água destilada e esterilizada (ADE). Cada repetição foi representada por um quadrante. A partir de então, procedeuse à avaliação do efeito dos indutores sobre a percentagem de germinação dos conídios até que houvesse aproximadamente 90\% de germinação dos conídios na testemunha. Foram considerados germinados conídios com tubo germinativo de tamanho igual ou superior ao conídio não germinado. $\mathrm{O}$ delineamento experimental utilizado foi o inteiramente casualizado em esquema fatorial 7 × 2, com seis concentrações mais uma testemunha absoluta para cada um dos dois indutores de resistência avaliado, e quatro repetições.

Determinação da atividade in vitro do ASM e do BABA sobre o crescimento micelial de $F$. oxysporum f. sp. cubense

O efeito de ASM e BABA sobre o crescimento micelial de $F$. oxysporum f. sp. cubense foi estudado em placas de Petri contendo $20 \mathrm{ml}$ de BDA. Para tanto foi procedida a transferência de uma gota de cada indutor em estudo (nas mesmas dosagens utilizadas para germinação de conídios) para um orifício feito no centro de uma placa de Petri, pela remoção de um disco de $10 \mathrm{~mm}$ de diâmetro. No orifício foi colocado um disco, $12 \mathrm{~mm}$ de diâmetro, obtido das bordas de uma cultura de F. oxysporum f. sp. cubense. A intervalos de 24 h o diâmetro da colônia era determinado estabelecendo-se a média de duas medidas tomadas em sentido diametralmente opostos.

O delineamento experimental utilizado foi inteiramente casualizado em esquema fatorial 7 × 2 , seis dosagens e uma testemunha com água esterilizada, para cada indutor de resistência avaliado, em cinco repetições, e dois indutores. Os dados foram submetidos à análise de variância determinandose a curva de regressão pelo programa estatístico SISVAR.

\section{Avaliação do efeito da aplicação de ASM e BABA em mudas micropropagadas de bananeira na severidade do mal-do-Panamá}

O trabalho foi conduzido sob condição de casa de vegetação, na Embrapa Mandioca e Fruticultura, localizada no município de Cruz da Almas, Bahia. Plantas micropropagadas, com $20 \mathrm{~cm}$ de altura, das variedades Maçã (altamente suscetível) e Grande Naine (resistente), foram transferidas para sacos de polietileno preto, contendo 1,8 1 do substrato reutilizado de Plantimax + fertilizantes minerais + fibra da casca de coco (1: 0,3: 1), previamente esterilizado com brometo de metila. As plantas foram pulverizadas com os indutores de resistência nas dosagens $0 ; 0,050 ; 0,100 ; 0,150$; 0,200 e 0,250 mg.ml ${ }^{-1}$ de ASM e $0 ; 0,525 ; 1,050 ; 1,575 ; 2,100$ e 2,625 mg. $\mathrm{ml}^{-1}$ de BABA sendo aplicados $7 \mathrm{ml}$ de cada solução por planta. Para cada indutor de resistência avaliado foram incluídos dois tipos de testemunhas: testemunha relativa, consistindo de plantas não pulverizadas com indutor e inoculadas com F. oxysporum f. sp. cubense, e testemunha absoluta, sem nenhum tratamento.

Fusarium oxysporum f. sp. cubense foi cultivado em meio de cultura BDA, pH 6, e incubado a temperatura aproximada de $25{ }^{\circ} \mathrm{C}$, durante oito dias. Após esse período 
obteve-se uma suspensão conidial, cuja concentração foi determinada em hemacitômetro tipo Neubauer e, ajustada para $10^{3}$ conídios. $\mathrm{ml}^{-1}$. As plantas foram inoculadas a quatro, seis, e oito semanas após a indução de resistência, mediante imersão das raízes na suspensão do inóculo de $F$. oxysporum f. sp. cubense por $1 \mathrm{~h}$.

A severidade de doença foi avaliada 20 dias após a inoculação, mediante corte transversal do rizoma, atribuindose notas de 1 a 6 conforme escala proposta por Cordeiro \& Dantas (1993). Para avaliação da severidade de doença, comparou-se cada tratamento com as respectivas testemunhas relativa e absoluta.

O delineamento experimental foi inteiramente casualizado, em esquema fatorial $7 \times 2 \times 2 \times 3$, representado pelas cinco dosagens de cada indutor mais duas testemunhas (relativa e absoluta), dois indutores, duas variedades e três períodos de inoculação, após aplicação do indutor de resistência. Foram utilizadas dez repetições por tratamento. Os dados foram submetidos à análise de variância individual para cada período avaliada; e a análise conjunta considerando os três períodos simultaneamente, sendo as médias comparadas pelo teste de Tukey ao nível de 5\% de probabilidade, utilizando-se o programa SAS.

\section{RESULTADOS E DISCUSSÃO}

Efeito in vitro de ASM sobre a germinação de conídios e crescimento micelial de $\boldsymbol{F}$. oxysporum f. sp. cubense

A curva de regressão (Figura 1) possibilita inferir que a maior dosagem $\left(0,500 \mathrm{mg} \cdot \mathrm{ml}^{-1}\right)$ de ASM inibiu a germinação de conídios quando comparada à testemunha. Os demais pontos da curva e as médias indicam um possível incremento na germinação de conídios comparando-se à testemunha. As maiores dosagens do ASM tenderam a desfavorecer, enquanto que as menores dosagens testadas até favoreceram a germinação de conídios. Resultados similares foram relatados por Pascholati et al. (1998) e Tosi \& Zazzerini (2000) que constataram efeito inibidor deste indutor sobre a germinação de conídios de Colletotrichum graminicola (Ces.) G. W. Wilson e de esporocarpos de Glomus mossea (Nicol. et Gerd.) Gedermann et Trappe à medida que aumentava a dosagem de ASM in vitro.

Os dados não propiciaram o ajuste de uma equação de regressão (Figura 1) que pudesse explicar o comportamento do crescimento micelial de $F$. oxysporum f. sp. cubense em presença de solução aquosa com o ASM nas dosagens utilizadas, comparadas à testemunha absoluta. No entanto, verifica-se que este indutor promoveu maior crescimento micelial nas diferentes dosagens utilizadas.

Efeito in vitro de BABA sobre germinação de conídios e crescimento micelial de $F$. oxysporum f. sp. cubense

Não foi possível ajustar uma curva de regressão (Figura 2) para as médias de germinação de conídios, contudo a análise dos pontos em separado na curva de dispersão comparados com a testemunha, permitiu inferir que não houve um efeito direto de BABA sobre a germinação de conídios. BABA, nas dosagens testadas não interferiu no crescimento micelial de $F$. oxysporum f. sp. cubense quando comparadas à testemunha. Cohen (1994) e Tosi \& Zazzerini (2000) obtiveram resultados semelhantes ao testar BABA sobre Plasmopora helianthi (Novot) e Phytophthora infestans (Mont.) De Bary, respectivamente, in vitro.

\section{Efeito de ASM e BABA em mudas micropropagadas de bananeira na severidade do mal-do-Panamá}

Não se constatou interação significativa entre época de inoculação, variedade e indutores de resistência/dosagens, contudo houve interação significativa entre variedade e indutores de resistência/dosagens. A análise de cada época, separadamente (Tabela 1), mostra que BABA, quando aplicado na dosagem 2,100 mg.ml ${ }^{-1}$ sobre a banana 'Maçã', quatro semanas antes da inoculação com $F$. oxysporum $\mathrm{f}$. sp. cubense, foi capaz de reduzir a severidade de doença em 35,29\% diferindo significativamente da testemunha relativa. Para a variedade Grande Naine, a análise das médias dos três períodos permitiu inferir que BABA, $0,525 \mathrm{mg} \cdot \mathrm{ml}^{-1}$ foi capaz de reduzir significativamente a severidade de doença em $21,55 \%$ quando comparada com a testemunha inoculada. Estes resultados estão de acordo com os obtidos por Siegrist et al. (2000), que conseguiram reduzida proteção contra Tobacco mosaic virus (TMV) família Tombusviridae e gênero Tobamovirus em plantas de fumo (Nicotiana tawbaccum L.)quando utilizaram dosagens de BABA inferiores a 0,525 $\mathrm{mg} \cdot \mathrm{ml}^{-1}$. A despeito de sua comprovada ação como indutor de

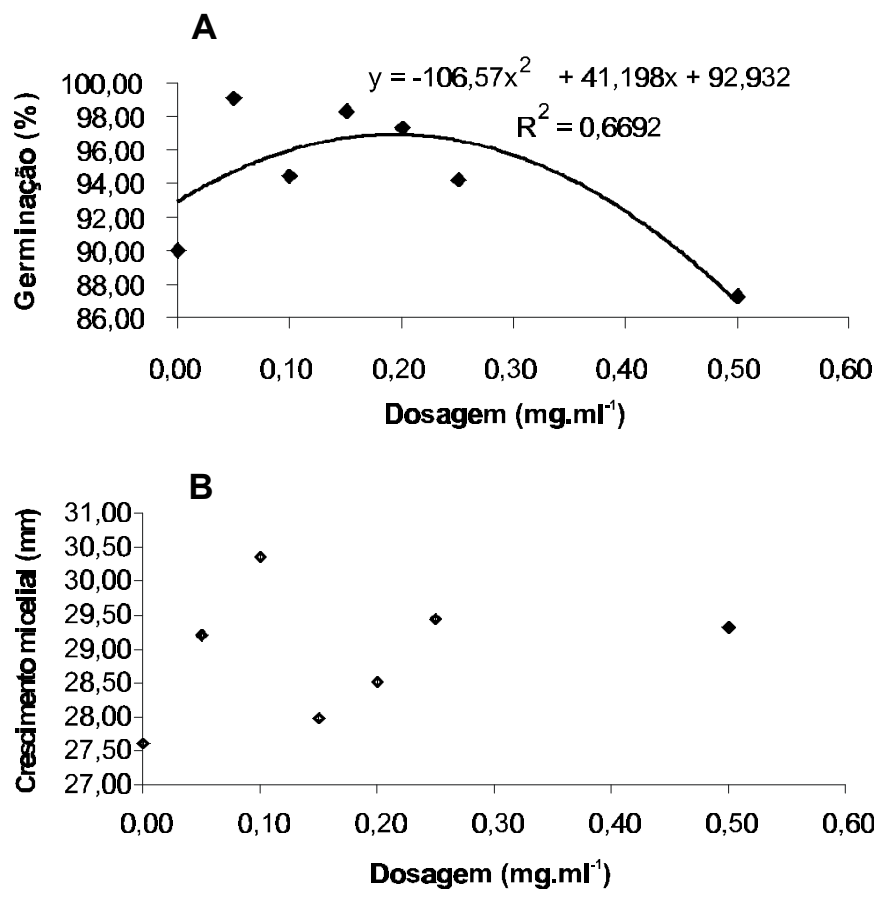

FIG. 1 - Efeito de dosagens de acibenzolar-S-methyl (ASM) sobre a germinação de conídios (A) e crescimento micelial (B) de Fusarium oxysporum f. sp. cubense. 


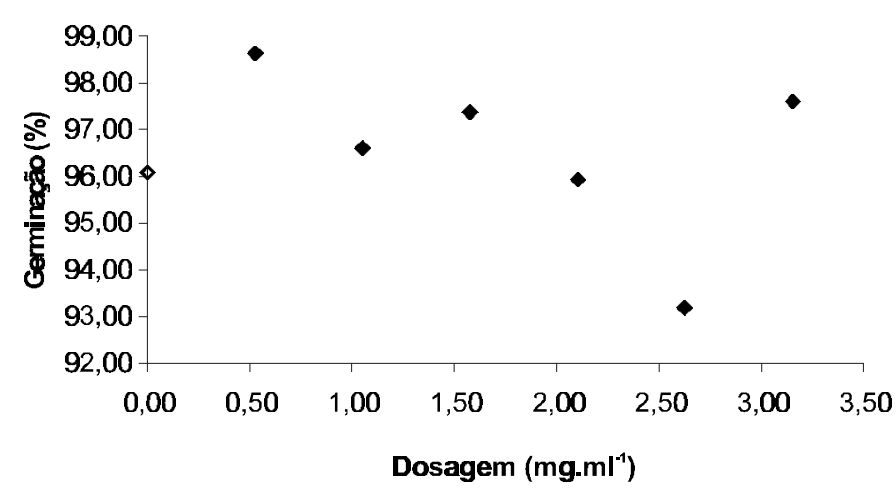

FIG. 2 - Efeito de dosagens de DL-b-amino-n-butyric acid (BABA) sobre a germinação de conídios de Fusarium oxysporum f. sp. cubense.

resistência em outros fitopatossistemas (Görlach et al., 1996), ASM não mostrou eficiência na redução da severidade do mal-do-Panamá em bananeira tanto 'Maçã̃', quanto 'Grande Naine'. A indução de resistência sistêmica adquirida por BABA já foi comprovada contra muitas espécies de Fusarium, a exemplo de F. oxysporum f. sp. tracheiphilum (E.F. Smith) Snyder \& Hansen (Rodrigues, 2003), sendo este o primeiro relato de eficiência desse indutor contra $F$. oxysporum f. sp. cubense.

Uma melhor resposta da banana 'Maçã' à indução de mecanismos de resistência por BABA, quando comparada à proteção induzida pelo mesmo indutor na variedade Grande Naine, pode estar relacionada à sua maior suscetibilidade ao patógeno, e/ou ao fato da ativação de SAR por BABA estar associada a altas dosagens para a maioria dos fitopatossistemas (Siegrist et al., 2000). De acordo com Cohen (2002), a concentração de BABA requerida para alcançar efetiva $(\cong 90 \%)$ resistência controlada depende de condições do hospedeiro, do patógeno e do modo de aplicação. A interação genótipo/indutor de resistência foi demonstrada no patossistema pepino/ Colletotrichum orbiculare (Berk. \& Mont.) Von Arx, no qual as rizobactérias Pseudomonas putida (Trevisan) Migular e Serratia marcescens Bizio foram utilizadas como agentes indutores de resistência sistêmica adquirida (Liu et al., 1995).

De acordo com Beckman \& Zarrogian (1967), variedades suscetíveis de banana, como 'Maçã', produzem substâncias gelatinosas como resposta à penetração de $F$. oxysporum f. sp. cubense, e respondem com formação de tiloses embora tardiamente, não impedindo a colonização dos seus tecidos por F. oxysporum f. sp. cubense. Além da formação

TABELA 1 - Efeito de cinco dosagens $\left(\mathrm{mg}^{-1} \mathrm{ml}^{-1}\right)$ e três períodos de aplicação de acibenzolar-S-methyl (ASM) e DL-b-amino-n-butyric acid (BABA) sobre a severidade do malacibenzolar-S-methyl-do-Panamá em duas variedades de bananeira (Musa spp.) inoculadas com Fusarium oxysporum f. sp. cubense

\begin{tabular}{|c|c|c|c|c|c|c|c|c|}
\hline \multicolumn{4}{|c|}{ BABA } & \multicolumn{5}{|c|}{ ASM } \\
\hline \multicolumn{4}{|c|}{ PERÍODO DE INCULAÇÃO } & \multicolumn{5}{|c|}{ PERÍODO DE INCULAÇ̃̃O } \\
\hline $\mathbf{D}^{1}$ & $\mathbf{E 1 ^ { 2 }}$ & E2 & -MÉDIAS & $\mathbf{D}^{1}$ & $\mathbf{E} 1^{2}$ & $\mathbf{E 2}$ & $\mathbf{E 3}$ & -MÉDIAS \\
\hline \multicolumn{4}{|c|}{ BANANA MAÇÃ } & \multicolumn{5}{|c|}{ BANANA MAÇ̃̃ } \\
\hline 0,525 & $2,70 \mathbf{a}^{3}$ & 3,60 a $2,80 a^{3}$ & $3,03 \mathbf{a b}^{3}$ & 0,050 & $2,70 \mathbf{a}^{3}$ & $3,00 \mathbf{a}$ & $2,80 a^{3}$ & $2,83 \mathbf{a}^{3}$ \\
\hline 1,050 & $2,40 \mathbf{a}$ & 2,90 a 2,40 a & $2,57 \mathbf{a b}$ & 0,100 & $3,20 \mathbf{a}$ & $3,50 \mathbf{a}$ & $3,20 \mathbf{a}$ & $3,30 \mathbf{a}$ \\
\hline 1,575 & $3,70 \mathbf{a}$ & 2,55 a $3,50 \mathbf{a}$ & $3,28 \mathbf{a}$ & 0,150 & $2,44 \mathbf{a}$ & $3,10 \mathbf{a}$ & $3,60 \mathrm{a}$ & $3,07 \mathbf{a}$ \\
\hline 2,100 & $2,20 \mathrm{~b}$ & 2,66 a 2,55 a & $2,46 \mathrm{~b}$ & 0,200 & $3,10 \mathbf{a}$ & $3,10 \mathbf{a}$ & $3,10 \mathbf{a}$ & $3,01 \mathbf{a}$ \\
\hline 2,625 & $2,60 \mathrm{a}$ & 2,50 a $2,30 \mathbf{a}$ & $2,47 \quad b$ & 0,250 & $2,60 \mathrm{a}$ & $3,33 \mathbf{a}$ & $2,60 \mathrm{a}$ & $2,83 \mathbf{a}$ \\
\hline 0,000 & $3,40 \mathrm{a}$ & 2,70 a $2,50 \mathbf{a}$ & $2,87 \mathbf{a b}$ & 0,000 & $3,40 \mathrm{a}$ & $2,70 \mathbf{a}$ & $2,50 \mathbf{a}$ & $2,87 \mathbf{a}$ \\
\hline \multicolumn{4}{|c|}{ BANANA G. NAINE } & \multicolumn{5}{|c|}{ BANANA G. NAINE } \\
\hline 0,525 & $1,70 \mathbf{a}$ & 2,40 b $2,33 \mathbf{a}$ & $2,14 \mathrm{~b}$ & 0,050 & $2,50 \mathbf{a}$ & $2,50 \mathbf{a}$ & $2,30 \mathbf{a}$ & $2,43 \mathbf{a}$ \\
\hline 1,050 & $2,30 \mathbf{a}$ & $2,70 \mathbf{a b} 2,30 \mathbf{a}$ & $2,43 \mathbf{a}$ & 0,100 & $2,10 \mathbf{a}$ & $2,60 \mathbf{a}$ & $2,10 \mathbf{a}$ & $2,27 \mathbf{a}$ \\
\hline 1,575 & $2,10 \mathbf{a}$ & $2,80 \mathrm{ab} 2,80 \mathrm{a}$ & $2,57 \mathbf{a}$ & 0,150 & $2,10 \mathbf{a}$ & $2,00 \mathbf{a}$ & $2,7 \mathbf{0} \mathbf{a}$ & $2,27 \mathbf{a}$ \\
\hline 2,100 & $2,70 \mathbf{a}$ & $3,66 \mathbf{a} \quad 3,30 \mathbf{a}$ & $3,09 \mathbf{a}$ & 0,200 & $2,60 \mathrm{a}$ & $2,10 \mathbf{a}$ & $2,50 \mathbf{a}$ & $2,40 \mathbf{a}$ \\
\hline 2,625 & $2,10 \mathbf{a}$ & 2,20 b $2,80 \mathbf{a}$ & $2,37 \mathbf{a}$ & 0,250 & $2,10 \mathbf{a}$ & $2,13 \mathbf{a}$ & $3,10 \mathbf{a}$ & $2,46 \mathbf{a}$ \\
\hline 0,000 & $2,70 \mathbf{a}$ & 2,55 ab $2,90 \mathbf{a}$ & $2,72 \mathbf{a}$ & 0,000 & $2,70 \mathbf{a}$ & $2,55 \mathbf{a}$ & $2,90 \mathrm{a}$ & $2,72 \mathbf{a}$ \\
\hline CV (\%) & 46,71 & $\begin{array}{ll}34,88 & 37,09 \\
\end{array}$ & 39,58 & $\mathrm{CV}(\%)$ & 46,71 & 34,88 & 37,09 & 39,58 \\
\hline
\end{tabular}

${ }^{1}$ Dosagem, mg.ml ${ }^{-1}$; 2 Inoculação a quatro (E1), seis (E2) e oito (E3) semanas após aplicação do indutor de resistência sistêmica adquirida; ${ }^{3}$ Médias seguidas pela mesma letra minúscula na coluna não diferem significativamente entre si a $5 \%$ de probabilidade pelo teste de Tukey; ${ }^{x}$ Relativo à análise individual para cada época. ${ }^{y}$ Relativo à análise conjunta considerando todas as épocas. 
de gel e tiloses como respostas de defesa, Ascensao \& Dubery (2003) comprovaram acúmulo de compostos fenólicos e lignina nas paredes celulares como parte de mecanismos de defesa nas raízes de bananeiras. Também, Mace (1963) constatou aumento no teor de fenóis em células de raízes de banana Gros Michel infetadas por F. oxysporum f. sp. cubense. Segundo Beckman (2000), estas células estariam distribuídas em locais estratégicos ou aleatoriamente nas plantas onde os fenóis estariam acumulados nos vacúolos. Numa situação de estresse biótico ou abiótico, estas células sofreriam descompartimentação e seu conteúdo fenólico se oxidaria promovendo a suberização, lignificação e morte de células provocando por exemplo, um rápido confinamento de patógenos nestes tecidos mortos. Evidentemente que esses mecanismos são fundamentais nas respostas de defesa de plantas. Assim sendo, é possível que BABA ative estes mecanismos de resistência ao mal-do-Panamá em bananeiras. Os resultados obtidos sugerem que outras dosagens e diferentes épocas de aplicação sejam testadas, trazendo com isto novas informações quanto à eficiência dos indutores BABA e ASM no controle de F. oxysporum f. sp. cubense em bananeira.

\section{AGRADECIMENTOS}

Os autores expressam seus agradecimentos ao $\mathrm{CNPq}$, a UFRPE, a AEE, e a Embrapa Mandioca e Fruticultura pelo apoio à pesquisa. Agradecimentos são também devidos a Companhia de Promoção Agrícola (CAMPO) pelo fornecimento das mudas micropropagadas de bananeiras utilizadas nesse estudo e ao pesquisador Carlos Alberto da Silva Lêdo pelas análises estatísticas.

\section{REFERÊNCIAS BIBLIOGRÁFICAS}

ANUÁRIO Brasileiro da Fruticultura 2003 Santa Cruz do Sul: Ed. Gazeta Santa Cruz, 2003.

ASCENSAO, A.R.F.D.C. \& DUBERY, I.A. Soluble and wall-bound phenolics polimers in Musa acuminata roots exposed to elicitors from Fusarium oxysporum f. sp. cubense. Phytochemistry 63:679686. 2003.

BECKMAN, C.H. \& ZARROGIAN, G.E. Origin and composition of vascular gel in infected banana. Phythopatology 57:11-13. 1967.

BECKMAN, C.H. Phenolics-Storing cells: Keys to programmed cell dead and periderm formation in disease resistance and in general defence responses in plants? Physiological Molecular Plant Pathology 57:101-110. 2000.

COHEN, Y.R. $\beta$-Aminobutyric Acid-Induced Resistance Against Plant Pathogens. Plant Disease 86:448-457. 2002.

COHEN, Y.R. Local and systemic control of Phytophythora infestans in tomato plants by DL-3-butanoic acids. The American Phythological Society 84:55-59.1994.

CORDEIRO, Z.J.M. \& MATOS, A.P. Doenças da bananeira. In:
Freire, F.C., Cardoso, J.E. \& Viana, F.M.P. (Eds). Doenças de fruteiras tropicais de interesse agroindustrial. Brasília, DF. Embrapa informação tecnológica. 2003. pp.323-390.

CORDEIRO, Z.J.M. \& DANTAS, J.L.L. Rating bananas reaction to fusarium wilt in Brazil. Proceedings, International Symposium on reccent developments in banana cultivation technology, Taiwan. 1993. pp.85-88.

FIGUEIRA, A. Métodos não convencionais de melhoramento de bananeira. Anais, $5^{\circ}$ Simpósio Brasileiro sobre Bananicultura, Paracatu, MG. 2003. pp.156-162.

GÖRLACH, J., VOLRATH, S., KNAUF-BEITER, G., BECKHOVE, U., KOGEL, KARL-HEINZ, OSTENDORP, M., STAUB, T., WARD, E., KESSMANN, H. \& RYALS, J. Benzothiadiazole, a novel class of inducers of systemic acquired resistance in wheat. The Plant Cell 8:629-643. 1996.

KESSMANN, H., STAUB, T., HOFMANN, C., MAETZKE, T., HERZOG, J, WARD, E., UKNES, S. \& RYALS, J. Induction of systemic acquired resistance in plants by chemicals. Annual Review of Phytopathology 32:439-459. 1994.

LIU, L., KLOEPPER, J.W. \& TUZUN, S. Induction of systemic resistance in cucumber by plant growth-promoting rhizobacteria:duration of protection and effect of host resistance on protection and root colonization. Phytopathology 85:1064-1068. 1995.

MACE, M.E. Histochemical localization of phenols in health and diseased banana roots. Physiologia Plantarum 16:915-925. 1963.

MATOS, A.P., CORDEIRO, Z.J.M., SILVEIRA, J.S. \& FERREIRA, D.M.V. O mal-do-Panamá ou murcha de fusarium da bananeira. In: Anais, $1^{\circ}$ Simpósio norte mineiro sobre a cultura da banana, Nova Porteirinha, MG. 2001. pp.38-50.

MOREIRA, R.S. Banana: teoria e prática de cultivo. Campinas: Fundação Cargil. 1987.

PASCHOLATI, S.F., STANGARLIN, J.R, HOTO, F.V., PICCININ, E. \& OSSWALD, W. Efeito in vitro do ativador "Bion" no crescimento micelial e na germinação de conídios de Colletotrichum graminicola. Fitopatologia Brasileira 23:266. 1998. (Resumo)

QUERINO, C.M.B., MATOS, A.P., LARANJEIRA, D. \& COELHO, R.S.B. Indução de resistência em bananeira à infecção por Fusarium oxyporum f. sp. cubense. In: Anais, $5^{\circ}$ Simpósio Brasileiro sobre Bananicultura, Paracatu, MG. 2003. pp.173-176.

RODRIGUES, A.A.C. Resistência de caupi a Fusarium oxysporum f. sp. tracheiphilum: Avaliação de germoplasmas, indução de defesa e caracterização de mecanismos bioquímicos, estruturais e análise da capacidade funcional do xilema. (Tese de Doutorado). Recife. Universidade Federal Rural de Pernambuco, 2003.

ROSALES, F.E., RIVEROS, A.S. \& BALCAZAR, S. Fitoprotección y su importancia en el cultivo de las musáceas. In: Anais, $5^{\circ}$ Simpósio Brasileiro sobre Bananicultura, Paracatu, MG. 2003. pp.173-176.

SIEGRIST, J., OROBER, M. \& BUCHENAUER, H. DL- $\beta$ aminobutyric acid-mediated enhancement of resistance in tobacco to tobacco mosaic virus depends on the accumulation of salicylic acid. Physiological and Molecular Plant Pathology 56:95-106. 2000.

TOSI, L. \& ZAZZERINI, A. Interactions between Plasmopara helianthi, Glomus mosseae and two plant activators in sunflower plants. European Journal of Plant Pathopatology 106:735-744. 2000. 